\title{
Efficacy and safety of stereotactic body radiation therapy combined with transarterial chemoembolization for Chinese intermediate-to advanced-stage hepatocellular carcinoma patients: a systematic review and meta-analysis
}

\author{
Shou-Jie Zhao', Bai-Shu Dai', Zhong-Jun Shao², Xi-Lin Du',"\#, Wei-Lu Zhang ${ }^{2, \#, ~ Y o n g ~ L o n g ~}{ }^{2, \#}$ \\ 'Department of General Surgery, Tangdu Hospital of the Fourth Military Medical University, Xi'an 710038, China. \\ Department of Epidemiology, the Fourth Military Medical University, Xi'an 710032, China. \\ \#The authors contributed equally.
}

Correspondence to: Dr. Yong Long and Dr. Wei-Lu Zhang, Department of Epidemiology, the Fourth Military Medical University, No. 169 Changle west road, Xi'an 710032, China. E-mail: longyong@fmmu.edu.cn; zhangweilu@126.com; Dr. Xi-Lin Du, Department of General Surgery, Tangdu Hospital of the Fourth Military Medical University, No. 569 Xinsi Road, Xi'an 710038, China. E-mail: dxlin0705@163.com

How to cite this article: Zhao SJ, Dai BS, Shao ZJ, Du XL, Zhang WL, Long Y. Efficacy and safety of stereotactic body radiation therapy combined with transarterial chemoembolization for Chinese intermediate-to advanced-stage hepatocellular carcinoma patients: a systematic review and meta-analysis. Hepatoma Res 2019;5:17. http://dx.doi.org/10.20517/2394-5079.2018.116

Received: 27 Dec 2018 First Decision: 27 Feb 2019 Revised: 16 May 2019 Accepted: 16 May 2019 Published: 22 May 2019

Science Editor: Guang-Wen Cao Copy Editor: Cai-Hong Wang Production Editor: Jing Yu

\begin{abstract}
Aim: According to the current guidelines, transarterial chemoembolization (TACE) remains the first-line therapies for hepatocellular carcinoma (HCC) patients at Barcelona Clinic Liver Cancer (BCLC) B-stage and sorafenib is a small molecule target drug for BCLC C-stage. In clinical practice, clinicians have attempted to use stereotactic body radiation therapy (SBRT) plus TACE for treating intermediate- to advanced-stage HCC. However, the therapeutic effects are still inconsistent. This meta-analysis was conducted to elucidate the validity and safety of the combination therapy of SBRT plus TACE in the patients with intermediate-to advanced-stage HCC.
\end{abstract}

Methods: PubMed, MEDLINE, Web of Science, China Biology Medicine, Chinese Knowledge resources integrated and Chinese Scientific Journal Full-Text Database was searched from their inception date to November 2018. The survival rates (half-year, one-year and two-year) were analyzed and compared between the observation groups and the control groups. The negative conversion rate of AFP and the total effective rate were also assessed. Risk ratios $(\mathrm{RR})$ and $95 \% \mathrm{Cl}$ were calculated to express therapeutic effects.

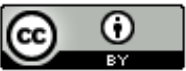

(C) The Author(s) 2019. Open Access This article is licensed under a Creative Commons Attribution 4.0 International License (https://creativecommons.org/licenses/by/4.0/), which permits unrestricted use, sharing, adaptation, distribution and reproduction in any medium or format, for any purpose, even commercially, as long as you give appropriate credit to the original author(s) and the source, provide a link to the Creative Commons license, and indicate if changes were made.

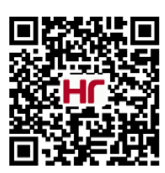


Results: A total of 1,210 patients from 13 eligible studies were included. The cooperation of TACE and SBRT notably ameliorated the whole survival rates of half-year, one-year, two-year, the negative conversion rate of AFP, and the total effective rate, compared with TACE or SBRT monotherapy [RR (the total effective rate), $1.412,95 \% \mathrm{Cl}$ : 1.3091.523, $P<0.001$ ], [RR (half-year survival rate), 1.196, 95\%Cl: 1.121-1.276, $P<0.001]$, [RR (one-year survival rate), 1.327, 95\%Cl: 1.236-1.424, $P<0.001]$, [RR (two-year survival rate), $1.479,95 \% \mathrm{Cl}: 1.284-1.703, P<0.001]$ and [RR (negative conversion rate of AFP), $1.756,95 \% \mathrm{Cl}: 1.502-2.059, P<0.001]$. Sensitivity analysis supported the above results.

Conclusion: Combination therapy of SBRT and TACE provides survival benefits in intermediate-to advanced-stage HCC patients compared to monotherapy of SBRT or TACE.

Keywords: Transcatheter arterial chemoembolization, hepatocellular carcinoma, stereotactic body radiation therapy, meta-analysis

\section{INTRODUCTION}

Hepatocellular carcinoma (HCC) is the third leading cause of cancer-related death and the fifth most common malignancy worldwide ${ }^{[1,2]}$. The incidence and mortality rates of HCC shows an increasing trend year by year ${ }^{[3]}$. Although the application of new HCC biomarkers and advanced imaging methods may improve the sensitivity and specificity of HCC in an early stage, a large proportion of HCC patients have been already at the intermediate-to advanced-stage at the time of diagnosis.

TACE, radiofrequency ablation, microwave ablation are widely used in clinically, and each of them has been proved to produce a great healing effect on patients in clinical practice ${ }^{[4-6]}$. However, the limited indications and contraindications restrict the clinical use of the monotherapy which may lead to a high recurrence rate. In recent years, researchers have tried relevant clinical trials to seek the treatment effect of combined treatment on patients with intermediate-and advanced-stage $\mathrm{HCC}^{[7-10]}$.

With the development of liver radiobiology and the significant progress of radiotherapy technology, SBRT has been gradually applied to HCC in the intermediate and advanced stage ${ }^{[11]}$. However, due to the relatively small sample size of related clinical trials and the lack of multi-center and large-sample randomized controlled studies, the efficacy of SBRT combined with TACE in the treatment of intermediate-and advancedstage HCC is difficult to draw definite conclusions. Therefore, the current meta-analysis was carried out to evaluate the efficacy and safety of combination therapy and provide evidence for clinical decision making.

\section{METHODS}

\section{Search strategy}

Studies were acquired via searching English databases, covering PubMed, MEDLINE, and the web of science (SCI). Chinese databases were also examined, including Chinese Knowledge resources integrated, Chinese Scientific Journal Full-Text Database and China Biology Medicine. The closing date for documents search was November, 2018,"transcatheter arterial chemoembolization" or TACE) or "transarterial chemoembolization" and "hepatocellular carcinoma" or "liver carcinoma" or "liver cancer" or "HCC" and ("stereotactic body radiation therapy" or "Gamma Knife") were used as search terms. Additionally, the references of relevant articles were also retrieved until no new potential material could be found.

\section{Study selection}

Including criteria for this meta-analysis were as follows: (1) randomized controlled trials and language limited to Chinese or English; (2) the studies that included an observation group adopted SBRT combined 


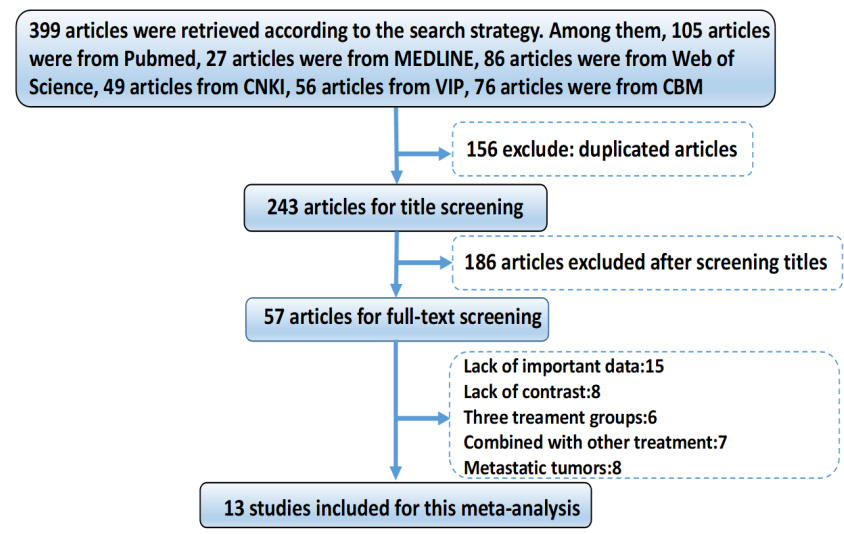

Figure 1. The earch and selection of eligible clinical studies. CNKI: Chinese Knowledge resources integrated; VIP: Chinese Scientific Journal Full-Text Database; CBM: China Biology Medicine

with TACE, while a control group passed TACE or SBRT merely; (3) HCC should be diagnosed by computed tomography (CT), magnetic resonance imaging or pathology; (4) the research results should include the total effective rate at least. The overall effective rate $=(C R+P R) /$ the total participants $\times 100 \%$, CR: tumor completely subsided and no re-occurrence of new tumors for at least four weeks; PR: tumor size shrunk more than $50 \%$ and no re-occurrence of new tumors for at least four weeks.

Publications complied with the following criteria were excluded: (1) the repetitive studies and unsuitable publication types, narrative reviews, systematic reviews, letters, comments, case reports or studies unrelated to our topics; (2) the studies including patients with metastatic liver cancer, under other therapies or three intervention procedures; (3) the studies including patients with severe cirrhosis, massive ascites or severe hepatic insufficiency; (4) the data were unable to be extracted from the reviews; (5) no control group was established in the reviews; (6) the studies including patients who had metastatic or recurrent liver carcinoma.

\section{Identification of eligible studies}

After searching the literature within several databases, 399 potentially relevant studies were identified initially. After the examination of titles and abstracts, 156 surveys were excluded and 57 articles were selected for fulltext screening. Finally, 13 studies were included for this meta-analysis. The study recruitment flowchart was shown in [Figure 1].

\section{Data extraction of the studies}

All included studies were published from 2008 to 2017. A total of 1,209 patients were enrolled, including 625 patients from the observation group and 584 patients from the control group. Among the patients, the male was 862 and female was 347. All patients were followed up for at least one year. Also, KPS score, Child-pugh score and TNM stage of the patients were also described. The data of the baseline characteristics of the patients in the included studies are presented in Table 1.

\section{Study quality assessment}

Two researchers (Shoujie Zhao and Baishu Dai) independently evaluated the included studies. The authors' name and institution were blinded to researchers. The risk of bias in RCTs was assessed according to the Cochrane Risk of Bias tool ${ }^{[12]}$ which is based on the following aspects: random sequence generation, allocation concealment, blinding of participants and personnel, blinding of outcome assessment, incomplete outcome data, and selective reporting. All the disagreements were discussed with the third researchers (Yong Long) to reach consensus. 
Table 1. Baseline characteristics of studies included in the meta-analysis

\begin{tabular}{|c|c|c|c|c|c|c|c|c|c|}
\hline \multirow{2}{*}{ Authors } & \multirow{2}{*}{$\begin{array}{c}\text { Published } \\
\text { year }\end{array}$} & \multirow{2}{*}{ Type of study } & \multirow{2}{*}{ Total number } & \multicolumn{2}{|c|}{ Number of participants } & \multirow{2}{*}{ KPS score } & \multirow{2}{*}{$\begin{array}{l}\text { Child-pugh } \\
\text { score }\end{array}$} & \multirow{2}{*}{ TNM stage } & \multirow{2}{*}{$\begin{array}{c}\text { Follow-up } \\
\text { time }\end{array}$} \\
\hline & & & & Observation & Control & & & & \\
\hline Ji et $a{ }^{[29]}$ & 2010 & RCT & 120 & 62 & 58 & $\geq 70$ & $A$ or $B$ & ND & 3 \\
\hline Liu et al. ${ }^{[30]}$ & 2016 & $\mathrm{RCT}$ & 86 & 43 & 43 & ND & ND & ND & 2 \\
\hline Luo et al..$^{[31]}$ & 2015 & $\mathrm{RCT}$ & 74 & 38 & 36 & ND & $A$ or $B$ & ND & 2 \\
\hline Pan et al. ${ }^{[32]}$ & 2015 & $\mathrm{RCT}$ & 84 & 47 & 37 & $\geq 70$ & $A$ or $B$ & $\geq$ II & 1 \\
\hline Sha et al. ${ }^{[33]}$ & 2013 & $\mathrm{RCT}$ & 105 & 52 & 53 & $\geq 60$ & $\geq B$ & ND & 1 \\
\hline Song et $a l^{[34]}$ & 2016 & $\mathrm{RCT}$ & 78 & 39 & 39 & ND & $A$ or $B$ & ND & 2 \\
\hline Sun et al. ${ }^{[35]}$ & 2014 & $\mathrm{RCT}$ & 62 & 32 & 30 & ND & $A$ or $B$ & ND & 1 \\
\hline Wei et $a !_{.}^{[36]}$ & 2009 & $\mathrm{RCT}$ & 104 & 52 & 52 & $\geq 60$ & $\geq B$ & $\geq$ III & 1 \\
\hline Xiu et al. ${ }^{[37]}$ & 2011 & RCT & 48 & 25 & 23 & $\geq 60$ & $A$ or $B$ & $\geq$ III & 1 \\
\hline Yang et al. ${ }^{[38]}$ & 2012 & $\mathrm{RCT}$ & 259 & 135 & 124 & ND & $\geq B$ & $\geq$ II & 2 \\
\hline Ye et al..$^{[39]}$ & 2011 & $\mathrm{RCT}$ & 62 & 30 & 32 & ND & $A$ or $B$ & ND & 2 \\
\hline Zhang et al. ${ }^{[40]}$ & 2010 & RCT & 72 & 36 & 36 & ND & ND & ND & 1 \\
\hline Zhou et al. ${ }^{[41]}$ & 2011 & RCT & 56 & 34 & 22 & $\geq 70$ & $A$ or $B$ & ND & 5 \\
\hline
\end{tabular}

KPS: Karnofsky scores; ND: Not described; RCT: randomized controlled trial; TACE: transcatheter arterial chemoembolization; SBRT: stereotactic body radiation therapy

\section{Statistical analysis}

Comprehensive Meta-Analysis V2 software was used in the data analysis. Pooled risk ratios (RRs) and 95\%CI were calculated to express therapeutic effects which were identified to be statistically significant if $P$ value $<0.05$. The heterogeneity was assessed usingthe $I^{2}$ statistic and associated $P$ values. Statistically, heterogeneity was deemed to haveexisted among the studies if $P$ value $<0.1$ or $I^{2}>50.00 \%$. A random-effect model was used to analyze the results if the heterogeneity existed. On the contrary, the fixed-effect model was used. Publication bias was assessed by the outcomes of the Egger test and the Begg test. If the number of included studies was less than 5, publication bias was not assessed.

\section{RESULTS}

\section{Total effective rate}

The results of the total effective rates were reported in 13 studies. No statistical heterogeneity was found among the studies, and a fixed-effect model was used $\left(P=0.791, I^{2}=0.00 \%\right)$. The results showed that the tumor response in the combined therapy group (TACE + SBRT) was significantly higher than that of the monotherapy group ( $\mathrm{RR}=1.412,95 \% \mathrm{CI}: 1.309-1.523, P<0.001)$. The Egger test $(P=0.124)$ and the Begg test $(P=0.0769)$ revealed no publication bias. The result of the total effective rates was shown in [Figure 2].

\section{Half-year survival}

There were only 4 out of 13 studies included in the half-year follow up the group, and the rest were not included. No statistical heterogeneity was found among the studies, and a fixed-effect model was used for meta-analysis $\left(P=0.917>0.1, I^{2}=0.00 \%\right)$. The results showed that the half-year survival of the combined therapy group $(\mathrm{TACE}+\mathrm{SBRT})$ was significantly higher than that of the monotherapy group $(\mathrm{RR}=1.196,95 \% \mathrm{CI}: 1.121-1.276$, $P<0.001$ ). The result of the half-year survival was shown in [Figure 3].

\section{One-year survival rate}

The results of the one-year survival rate were reported in 13 studies. No statistical heterogeneity was found among the studies, and a fixed-effect model was selected $\left(P=0.793>0.10, I^{2}=0.00 \%\right)$. The results showed that the 1-year survival rate of the combined therapy group (TACE + SBRT) was higher than that of the TACE monotherapy group $(\mathrm{RR}=1.326,95 \% \mathrm{CI}: 1.234-1.424, P<0.001)$. The Egger test $(P=0.10092)$ and the Begg test $(P=0.0509)$ revealed no publication bias. The result of one-year survival rate was shown in [Figure 4 ]. 


\begin{tabular}{|c|c|c|c|c|c|c|c|c|c|c|c|}
\hline \multirow[t]{2}{*}{$\underline{\text { Study name }}$} & \multicolumn{2}{|c|}{ Events / Total } & \multicolumn{5}{|c|}{ Statistics for each study } & \multicolumn{4}{|c|}{$\underline{\text { Risk ratio and } 95 \% \mathrm{Cl}}$} \\
\hline & $\begin{array}{c}\text { TACE } \\
\text { and SBRT }\end{array}$ & $\begin{array}{c}\text { TACE } \\
\text { or SBRT }\end{array}$ & $\begin{array}{l}\text { Risk } \\
\text { ratio }\end{array}$ & $\begin{array}{l}\text { Lower } \\
\text { limit }\end{array}$ & $\begin{array}{c}\text { Upper } \\
\text { limit }\end{array}$ & Z-Value & p-Value & & & & \\
\hline Ye et al & $26 / 30$ & $20 / 32$ & 1.387 & 1.024 & 1.877 & 2.116 & 0.034 & & 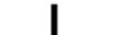 & + & | \\
\hline Sha et al & $48 / 52$ & $36 / 53$ & 1.359 & 1.112 & 1.661 & 2.992 & 0.003 & & & & \\
\hline Xiv et al & $16 / 25$ & $9 / 23$ & 1.636 & 0.908 & 2.946 & 1.639 & 0.101 & & & + & \\
\hline Zhang et al & $31 / 36$ & $24 / 36$ & 1.292 & 0.990 & 1.685 & 1.888 & 0.059 & & & + & \\
\hline Yang et al & $113 / 135$ & $63 / 124$ & 1.648 & 1.364 & 1.989 & 5.191 & 0.000 & & & + & \\
\hline Luo et al & $26 / 38$ & $15 / 36$ & 1.642 & 1.055 & 2.557 & 2.195 & 0.028 & & & + & \\
\hline Ji et al & $49 / 62$ & $35 / 58$ & 1.310 & 1.025 & 1.673 & 2.159 & 0.031 & & & + & \\
\hline Liu et al & $35 / 43$ & $24 / 43$ & 1.458 & 1.078 & 1.972 & 2.449 & 0.014 & & & + & \\
\hline Pan et al & $38 / 47$ & $19 / 37$ & 1.574 & 1.117 & 2.219 & 2.593 & 0.010 & & & + & \\
\hline Wei et al & $48 / 52$ & $39 / 52$ & 1.231 & 1.033 & 1.467 & 2.320 & 0.020 & & & + & \\
\hline Song et al & $27 / 39$ & $16 / 39$ & 1.688 & 1.097 & 2.596 & 2.382 & 0.017 & & & + & \\
\hline Sun et al & $28 / 32$ & $19 / 30$ & 1.382 & 1.021 & 1.869 & 2.097 & 0.036 & & & + & \\
\hline \multirow{4}{*}{ Zhou et al } & $27 / 34$ & $11 / 22$ & 1.588 & 1.011 & 2.495 & 2.008 & 0.045 & & & + & \\
\hline & & & 1.412 & 1.309 & 1.523 & 8.966 & 0.000 & & & t & \\
\hline & & & & & & & & 0.01 & 0.1 & 1 & 100 \\
\hline & & & & & & & & & ours A & Favours B & \\
\hline
\end{tabular}

\section{Meta Analysis}

Figure 2. Tumor response comparing transarterial chemoembolization (TACE) plus stereotactic body radiation therapy (SBRT) with TACE or SBRT monotherapy in intermediate-to advanced-stage hepatocellular carcinoma patients

\section{Meta Analysis}

\begin{tabular}{|c|c|c|c|c|c|c|c|c|c|c|c|c|c|}
\hline \multirow[t]{2}{*}{ Study name } & \multicolumn{2}{|c|}{ Events / Total } & \multicolumn{5}{|c|}{ Statistics for each study } & & \multicolumn{5}{|c|}{ Risk ratio and $95 \% \mathrm{Cl}$} \\
\hline & $\begin{array}{c}\text { TACE } \\
\text { and SBRT }\end{array}$ & $\begin{array}{c}\text { TACE } \\
\text { or SBRT }\end{array}$ & $\begin{array}{l}\text { Risk } \\
\text { ratio }\end{array}$ & $\begin{array}{l}\text { Lower } \\
\text { limit }\end{array}$ & $\begin{array}{l}\text { Upper } \\
\text { limit }\end{array}$ & Z-Value & p.Value & $\begin{array}{l}\text { Relative } \\
\text { weight }\end{array}$ & & & & & \\
\hline Yeetal & $30 / 30$ & $26 / 32$ & 1.225 & 1.029 & 1.459 & 2.276 & 0.023 & 13.61 & & & + & & \\
\hline Yang et al & $130 / 135$ & $102 / 124$ & 1.171 & 1.072 & 1.279 & 3.502 & 0.000 & 53.54 & & & t & & \\
\hline Luo et al & $38 / 38$ & $29 / 36$ & 1.238 & 1.048 & 1.462 & 2.517 & 0.012 & 15.04 & & & + & & \\
\hline \multirow[t]{4}{*}{ Song et al } & $39 / 39$ & $32 / 39$ & 1.215 & 1.043 & 1.416 & 2.500 & 0.012 & 17.81 & & & + & & \\
\hline & & & 1.196 & 1.121 & 1.276 & 5.434 & 0.000 & & & & i & & \\
\hline & & & & & & & & & 0.01 & 0.1 & 1 & 10 & 100 \\
\hline & & & & & & & & & & Favours A & & Favours B & \\
\hline
\end{tabular}

Meta Analysis

Figure 3. Meta-analysis of the half-year survival in 4 studies comparing transarterial chemoembolization (TACE) plus stereotactic body radiation therapy (SBRT) with TACE or SBRT monotherapy in intermediate-to advanced-stage hepatocellular carcinoma patients

\section{Two-year survival rate}

There were only 6 out of 13 studies included in the two-year survival follow up the group and the rest were not added. No statistical heterogeneity was found among the studies, and a fixed-effect model was used $(P=0.930$ $\left.>0.1, I^{2}=0.00 \%\right)$. The results showed that the 2 -year survival of the combined therapy group (TACE + SBRT) was significantly higher than that of the monotherapy group ( $\mathrm{RR}=1.153,95 \% \mathrm{CI}: 1.282-1.783, P<0.001)$. The Egger test $(P=0.36738)$ and the Begg test $(P=0.57303)$ revealed no publication bias. The result of the two-year survival rate was shown in [Figure 5].

\section{The negative conversion rate of AFP}

The negative conversion rate of AFP was reported in 6 studies. A random-effect model was used to analyse the result on account of the statistical heterogeneity which was found among the studies $\left(P=0.045, I^{2}=56.00 \%\right)$. 
Meta Analysis

\begin{tabular}{|c|c|c|c|c|c|c|c|c|c|c|c|c|c|}
\hline \multirow{2}{*}{ Study name } & \multicolumn{2}{|c|}{ Events / Total } & \multicolumn{5}{|c|}{ Statistics for each study } & & \multicolumn{5}{|c|}{ Risk ratio and $95 \% \mathrm{Cl}$} \\
\hline & $\begin{array}{c}\text { TACE } \\
\text { and SBRT }\end{array}$ & $\begin{array}{l}\text { TACE } \\
\text { or SBRT }\end{array}$ & $\begin{array}{l}\text { Risk } \\
\text { ratio }\end{array}$ & $\begin{array}{l}\text { Lower } \\
\text { limit }\end{array}$ & $\begin{array}{l}\text { Upper } \\
\text { limit }\end{array}$ & Z-Value & $\mathrm{p}$-Value & $\begin{array}{c}\text { Relative } \\
\text { weight }\end{array}$ & & & & & \\
\hline Ye etal & $26 / 30$ & $20 / 32$ & 1.387 & 1.024 & 1.877 & 2.116 & 0.034 & 5.53 & & & + & & \\
\hline Sha et al & $46 / 52$ & $38 / 53$ & 1.234 & 1.015 & 1.500 & 2.106 & 0.035 & 13.27 & & & + & & \\
\hline Xiu et al & $20 / 25$ & $13 / 23$ & 1.415 & 0.941 & 2.130 & 1.667 & 0.096 & 3.04 & & & + & & \\
\hline Zhang et al & $29 / 36$ & $21 / 36$ & 1.381 & 1.003 & 1.900 & 1.981 & 0.048 & 4.98 & & & + & & \\
\hline Yang et al & $116 / 135$ & $81 / 124$ & 1.315 & 1.138 & 1.521 & 3.698 & 0.000 & 24.05 & & & + & & \\
\hline Luo et al & $33 / 38$ & $20 / 36$ & 1.563 & 1.138 & 2.147 & 2.759 & 0.006 & 5.04 & & & + & & \\
\hline Ji etal & $45 / 62$ & $39 / 58$ & 1.079 & 0.853 & 1.367 & 0.635 & 0.526 & 9.12 & & & + & & \\
\hline Liu et al & $35 / 43$ & $29 / 43$ & 1.207 & 0.938 & 1.553 & 1.462 & 0.144 & 7.99 & & & + & & \\
\hline Pan et al & $35 / 47$ & $17 / 37$ & 1.621 & 1.100 & 2.388 & 2.442 & 0.015 & 3.38 & & & + & & \\
\hline Wei et al & $46 / 52$ & $34 / 52$ & 1.353 & 1.085 & 1.687 & 2.683 & 0.007 & 10.42 & & & + & & \\
\hline Song et al & $35 / 39$ & $22 / 39$ & 1.591 & 1.184 & 2.138 & 3.079 & 0.002 & 5.81 & & & + & & \\
\hline Sun et al & $25 / 32$ & $17 / 30$ & 1.379 & 0.959 & 1.981 & 1.735 & 0.083 & 3.86 & & & + & & \\
\hline \multirow[t]{4}{*}{ Zhou et al } & $28 / 34$ & $13 / 22$ & 1.394 & 0.952 & 2.040 & 1.708 & 0.088 & 3.50 & & & + & & \\
\hline & & & 1.326 & 1.234 & 1.424 & 7.754 & 0.000 & & & & 1 & & | \\
\hline & & & & & & & & & 0.01 & 0.1 & 1 & 10 & 100 \\
\hline & & & & & & & & & & Favours A & & Favours B & \\
\hline
\end{tabular}

Meta Analysis

Figure 4. Meta-analysis of the one-year survival rate in 13 studies comparing transarterial chemoembolization (TACE) plus stereotactic body radiation therapy (SBRT) with TACE or SBRT monotherapy for intermediate-to advanced-stage hepatocellular carcinoma patients

\section{Meta Analysis}

\begin{tabular}{|c|c|c|c|c|c|c|c|c|c|c|c|c|}
\hline \multirow[t]{2}{*}{$\underline{\text { Study name }}$} & \multicolumn{2}{|c|}{ Events / Total } & \multicolumn{5}{|c|}{$\underline{\text { Statistics for each study }}$} & \multirow[b]{2}{*}{$\begin{array}{l}\text { Relative } \\
\text { weight }\end{array}$} & \multicolumn{4}{|c|}{ Risk ratio and $95 \% \mathrm{Cl}$} \\
\hline & $\begin{array}{c}\text { TACE } \\
\text { and SBRT }\end{array}$ & $\begin{array}{l}\text { TACE } \\
\text { or SBRT }\end{array}$ & $\begin{array}{l}\text { Risk } \\
\text { T ratio }\end{array}$ & $\begin{array}{c}\text { Lower } \\
\text { limit }\end{array}$ & $\begin{array}{c}\text { Upper } \\
\text { limit }\end{array}$ & Z-Value & p-Value & & & & & \\
\hline Liu et al & $37 / 43$ & $22 / 43$ & 1.682 & 1.226 & 2.306 & 3.226 & 0.001 & 24.94 & & & + & \\
\hline Luo et al & $34 / 38$ & $13 / 36$ & 2.478 & 1.583 & 3.878 & 3.970 & 0.000 & 12.40 & & & + & \\
\hline Pan et al & $9 / 33$ & $4 / 25$ & 1.705 & 0.592 & 4.905 & 0.989 & 0.323 & 2.23 & & & + & \\
\hline Song et al & $35 / 39$ & $14 / 39$ & 2.500 & 1.622 & 3.853 & 4.151 & 0.000 & 13.30 & & & + & \\
\hline Yang et al & $65 / 101$ & $46 / 95$ & 1.329 & 1.032 & 1.712 & 2.202 & 0.028 & 38.80 & & & + & \\
\hline \multirow[t]{4}{*}{ Ye et al } & $23 / 26$ & $9 / 26$ & 2.556 & 1.480 & 4.413 & 3.367 & 0.001 & 8.34 & & & + & \\
\hline & & & 1.759 & 1.502 & 2.059 & 7.014 & 0.000 & & & & 1 & \\
\hline & & & & & & & & & 0.01 & 0.1 & 10 & 100 \\
\hline & & & & & & & & & & Favours A & Favours B & \\
\hline
\end{tabular}

Meta Analysis

Figure 5. Meta-analysis of the two-year survival in 6 studies comparing transarterial chemoembolization (TACE) plus stereotactic body radiation therapy (SBRT) with TACE or SBRT monotherapy for intermediate-to advanced-stage hepatocellular carcinoma patients

The results showed that negative conversion rate of AFP of the combined therapy group (TACE + SBRT) was significantly higher than that of the monotherapy group ( $\mathrm{RR}=1.756,95 \% \mathrm{CI}: 1.502-2.059, P<0.001)$. The Egger test $(P=0.175)$ and the Begg test $(P=0.707)$ revealed no publication bias. The result of the nagative conversion rate of AFP was shown in [Figure 6].

\section{DISCUSSION}

This current meta-analysis aimed to assess the validity and safety of SBRT combined with TACE for patients in intermediate-to advanced-stage HCC. The pooled results showed that TACE plus SBRT notably ameliorated the total survival rates of half-year, one-year and two-year $(P<0.05)$. Combination treatment of SBRT and TACE were also benefited to the negative conversion rate of AFP and the total effective rate $(P<0.05)$. The results revealed that SBRT combined with TACE had superior efficacy than that of SBRT or TACE alone for HCC patients in intermediate-to advanced-stage. 
Meta Analysis

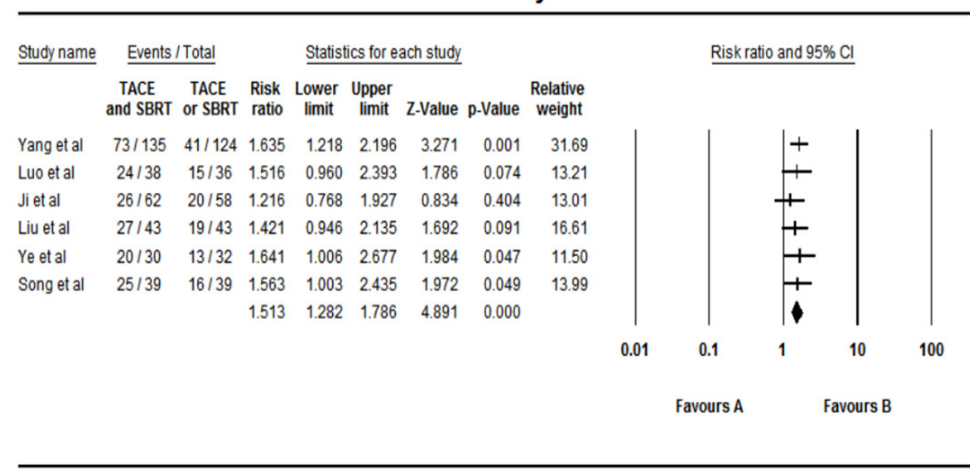

Meta Analysis

Figure 6. Meta-analysis of the negative conversion rate of AFP in 6 studies comparing transarterial chemoembolization (TACE) plus stereotactic body radiation therapy (SBRT) with TACE or SBRT monotherapy for intermediate-to advanced-stage hepatocellular carcinoma patients

HCC is a malignant tumor which seriously endangers human health. Due to the difficulty in early diagnosis and its hidden character, most patients are diagnosed at the intermediate- to advanced-stage. Sorafenib or lenvatinib is currently used as a first-line standard therapeutic agent for advanced HCC according to the BCLC criteria ${ }^{[13,14]}$. Besides, apatinib may be a substitute for HCC patients with sorafenib resistance in the future, especially for those with high expression of VEGF ${ }^{[15]}$. With the rapid development of clinical medicine, the appearance of more and more treatment methods which lead to no uniform suggestion for the treatment of intermediate to advanced HCC patients.

TACE is recognized as an alternative treatment option for intermediate-to advanced- HCC patients ${ }^{[16]}$. It is to inject chemotherapy drugs directly into tumor blood supply artery through a catheter which can improve local drug concentration of tumor to increase the ability to kill cancer cells, achieve embolization of tumor blood vessels and block the blood supply of a tumor, tumor tissue necrosis, shrinkage, and disappearance. However, tumor tissues could not be eliminated through TACE ${ }^{[17]}$. There are mainly three reasons. Firstly, after TACE, some infiltrating cells and metastatic liver cells are still alive, and repeated treatment by TACE may produce a specific resistance to chemotherapy drugs. Secondly, the liver tissue is damaged due to hypoxia and ischemia, embolization agents and chemotherapy drugs, which influences the clinical efficacy of transcatheter arterial chemoembolization. Thirdly, after TACE, part of the tumor tissue will recover blood supply. Therefore, although the short-term effectiveness of TACE is justifiable, it still has limitations, and the long-term effectivness remains unsatisfactory.

The liver is a radiosensitive organ which ranks only behind bone marrow, lymphoid tissue, and kidney ${ }^{[18]}$. As a result, in spite of the rapid development of radiotherapy for HCC, the efficacy was not significantly improved. In recent years, with the growth of stereotactic radiotherapy, SBRT is gradually appropriate for intermediate-to advanced-HCC ${ }^{[19-22]}$. SBRT delivers a high dose of radiation to HCC within a short period time and is effective and less invasive for the delivery of high radiation doses to the tumor with hypofractionation. Employing the high-dose irradiation to the tumor area which can reduce irradiation dose of the healthy liver tissue at the same time, SBRT can make the tumor vascular degrade and mortify, lower the blood supply of the cancer to achieve the goal of killing tumor cells. Besides, it is efficient that multiple lesions can be operated at the same time by the use of SBRT. The features of SBRT above, to a large extent, make up the defect of TACE.

Recently, the therapeutic role of SBRT combined with TACE for intermediate-to advanced-stage HCC has been emphasized more than before ${ }^{[23,24]}$. Jun and $\mathrm{Kim}^{[25]}$ showed that SBRT combined with TACE is a feasible 
option for patients with HCC $(\leq 5 \mathrm{~cm})$ without increased liver toxicity compared with TACE. Chung and Hwang $^{[26]}$ suggested that SBRT combined with TACE can be a therapeutic option for HCC at the caudate lobe with marginal resectability. In the study by Kang et al. ${ }^{[27]}$ stereotactic body radiation therapy combined with TACE in the treatment of primary HCC with portal vein cancer thrombus can significantly improve the local control rate, survival rate, the effective rate of portal vein cancer thrombus, and AFP improvement rate. Besides, SBRT before TACE may have superiority in protecting liver function. Furthermore, SBRT combined with TACE may be a useful complementary treatment approach for HCC $>5 \mathrm{~cm}$ in diameter ${ }^{[28]}$.

The application of SBRT combined with TACE in the treatment of intermediate-to advanced-HCC patients produced a synergistic therapeutic effect which may be related to the following factors: (1) TACE can shrink tumor volume and reduce normal liver tissue damage; (2) Chemotherapeutics have the effect of enhanced sensitivity for radiotherapy; (3) SBRT can denature vascular endothelial cells and block blood capillaries, prolong the storage time of iodide oil and drugs in the body, and avoid repeated TACE treatment; (4) TACE and SBRT have different therapeutic effects on cancer cells at various growth stages; (5) TACE can promote the transformation of the remaining cells from non-proliferative stage cells to the proliferative phase which can improve the sensitivity and the therapeutic effect of SBRT.

Six studies revealed that the side effects in the combined therapy group were slightly more substantial than those in the monotherapy group, such as decrease of hemoglobin, leukocyte, thrombocytopenia, gastrointestinal reactions, and liver function damage, but there was no significant difference between the experimental group and control group $(P>0.05)$. The prognosis of the patients generally did not be affected through the active symptomatic treatment ${ }^{[29,30,32,33,36,39]}$.

The results of our meta-analysis are subject to several limitations. Firstly, although a total of 13 studies including 1210 patients were enrolled and the whole studies selected were high-quality RCTs, the sample sizes of most studies were relatively small ${ }^{[29-41]}$. As a result, the studies selected maybe not capable of finding out the details of all aspects and performing more subgroup analyses to evaluate the effect of the patients treated by SBRT plus TACE compared with SBRT or TACE monotherapy. To verify and extend the observations, a more randomized controlled, multi-center, large sample of trials are necessary. Secondly, for the sake of clinical practice guidelines and ethical issues, there might be produced potential selection bias which may derive from the characteristics of the patients such as the age, the liver function, tumor size. The above limitations may influence the final results. Thirdly, due to lack of sufficient data, the sequence of the two therapies and the interval of them, the frequency of TACE and the dose of radiotherapy were not performed in this meta-analysis which was expected to be answered by further clinical studies. Fourthly, the included studies were all conducted in China, which may bring the regional bias.

In conclusion, compared to the treatment of TACE or SBRT alone, SBRT combined with TACE is a mild, safe and effective treatment which can extend the survival time and be beneficial to the prognosis of intermediateto advanced-stage HCC patients without any significant increase in severe untoward effects. Further studies should be performed to confirm the impact of the combined therapy.

\section{DECLARATIONS}

\section{Authors' contributions}

Discussed, agreed upon the content, contributed to the development and revision of the draft manuscripts, read and approved the final manuscript: all authors

Drafted the initial version: Zhao SJ, Dai BS

Contributed to constructive suggestions and modification: Shao ZJ

Developed the idea for the study and contributed useful criticism and suggestions: Du XL, Zhang WL, Long Y 


\section{Availability of data and materials}

Not applicable.

\section{Financial support and sponsorship}

This study was funded by the National Natural Science Foundations of China $(81773488,81172287)$.

\section{Conflicts of interest}

All authors declared that there are no conflicts of interest.

\section{Ethical approval and consent to participate}

Not applicable.

\section{Consent for publication}

Not applicable.

\section{Copyright}

(C) The Author(s) 2019.

\section{REFERENCES}

1. Wen T, Jin C, Facciorusso A, Donadon M. Multidisciplinary management of recurrent and metastatic hepatocellular carcinoma after resection: an international expert consensus. Hepatobiliary Surg Nutr 2018;7:353-71.

2. Bruix J, Reig M, Sherman M. Evidence-based diagnosis, staging, and treatment of patients with hepatocellular carcinoma. Gastroenterology 2016;150:835-53.

3. Hsiang JC, Wong GL, Tse YK. Statin and the risk of hepatocellular carcinoma and death in a hospital-based hepatitis B-infected population: a propensity score landmark analysis. J Hepatol 2015;63:1190-7.

4. Minocha J, Salem R, Lewandowski RJ. Transarterial chemoembolization and yttrium-90 for liver cancer and other lesions. Clin Liver Dis 2014;18:877-90

5. Xu J, Noda C, Erickson A, Mokkarala M, Charalel R, et al. Radiofrequency ablation vs. cryoablation for localized hepatocellular carcinoma: a propensity-matched population study. Anticancer Res 2018;38:6381-6.

6. Vogl TJ, Nour-Eldin NA, Hammerstingl RM, Panahi B. Microwave ablation (MWA): basics, technique and results in primary and metastatic liver neoplasms-review article. Rofo 2017;189:1055-66.

7. Yang Z, Chen G, Cui Y. The safety and efficacy of TACE combined with apatinib on patients with advanced hepatocellular carcinoma: a retrospective study. Cancer Biol Ther 2019;20:321-7.

8. Zhao M, Wang JP, Wu PH, Zhang FJ, Huang ZL, et al. Comparative analysis of TACE alone or plus RFA in the treatment of 167 cases of intermediate and advanced staged primary hepatocellular carcinoma. Zhonghua Yi Xue Za Zhi 2010;90:2916-21. (in Chinese)

9. Sato Y, Nishiofuku H, Yasumoto T, Nakatsuka A, Matsuo K. Multicenter phase II clinical trial of sorafenib combined with transarterial chemoembolization for advanced stage hepatocellular carcinomas (Barcelona clinic liver cancer stage C): STAB study. J Vasc Interv Radiol 2018;29:1061-7.

10. Wada Y, Takami Y, Matsushima H. The safety and efficacy of combination therapy of sorafenib and radiotherapy for advanced hepatocellular carcinoma: a retrospective study. Intern Med 2018;57:1345-53.

11. Meng M, Wang H, Zeng X, Zhao L, Yuan Z. Stereotactic body radiation therapy: A novel treatment modality for inoperable hepatocellular carcinoma. Drug Discov Ther 2015;9:372-9.

12. Higgins JP1, Altman DG. The cochrane collaboration's tool for assessing risk of bias in randomised trials. BMJ 2011;343:d5928.

13. Ikeda M, Morizane C. Chemotherapy for hepatocellular carcinoma: current status and future perspectives. Jpn J Clin Oncol 2018;48:103-14

14. Ikeda M, Mitsunaga S. Systemic chemotherapy for advanced hepatocellular carcinoma: past, present, and future. Diseases 2015;3:360-81.

15. Han Z, He Z, Wang C, Wang Q. The effect of apatinib in the treatment of sorafenib resistant metastatic hepatocellular carcinoma: a case report. Medicine (Baltimore) 2018;97:e13388.

16. Raoul JL, Forner A, Bolondi L, Cheung TT, Kloeckner R, et al. Updated use of TACE for hepatocellular carcinoma treatment: how and when to use it based on clinical evidence. Cancer Treat Rev 2018;72:28-36.

17. Yao E, Chen J. Efficacy of stereotactic body radiotherapy for recurrent or residual hepatocellular carcinoma after transcatheter arterial chemoembolization. Biomed Res Int 2018;2018:54881909.

18. Hehr T, Budach W, Lamprecht U. Experimental thermoradiotherapy in malignant hepatocellular carcinoma. Int J Radiat Oncol Biol Phys 2003;55:1374-80.

19. Honda Y, Kimura T, Aikata H. Stereotactic body radiation therapy combined with transcatheter arterialchemoembolization for small 
hepatocellular carcinoma. J Gastroenterol Hepatol 2013;28:530-6.

20. Kang J. Stereotactic body radiation therapy for inoperable hepatocellular carcinoma as a local salvage treatment after incomplete transarterial chemoembolization. Cancer 2012;118:5424-31.

21. Shui Y. Stereotactic body radiotherapy based treatment for hepatocellular carcinoma with extensive portal vein tumor thrombosis. Radiat Oncol 2018;13:188.

22. Moravan Michael J, Milano Michael T. SBRT for Hepatocellular Carcinoma: 8-Year Experience from a Regional Transplant Center. J Gastrointest Cancer 2018;49:463-9.

23. Li J. Transcatheter arterial chemoembolization in combination with stereotactic body radiation therapy in primary liver carcinoma: a systematic review and meta-analysis. Int J Clin Exp Med 2017;10:1816-27.

24. Lu XJ, Dong J. Safety and efficacy of TACE and gamma knife on hepatocellular carcinoma with portal vein invasion.Gut 2016;65:715-6.

25. Jun BG, Kim SG. Combined therapy of transarterial chemoembolization and stereotactic body radiation therapy versus transarterial chemoembolization for $\leq 5 \mathrm{~cm}$ hepatocellular carcinoma: propensity score matching analysis. PLoS One 2018;13:e 0206381.

26. Chung YK, Hwang S. Long-term complete response after transcatheter arterial chemoembolization and stereotactic body radiation therapy in a patient with hepatocellular carcinoma at the caudate lobe. Ann Hepatobiliary Pancreat Surg 2018;22:274-81.

27. Kang J, Nie Q, DU R, Zhang L, Zhang J, et al. Stereotactic body radiotherapy combined with transarterial chemoembolization for hepatocellular carcinoma with portal vein tumorthrombosis. Mol Clin Oncol 2014;2:43-50.

28. Su TS, Lu HZ, Cheng T, Zhou Y, Huang Y, et al. Long-term survival analysis in combined transarterial embolization and stereotactic body radiation therapy versus stereotactic body radiation monotherapy for unresectable hepatocellular carcinoma $>5 \mathrm{~cm}$. BMC Cancer 2016;16:834.

29. Ji H. Clinical analysis of stereotactic body radiation therapy combined with transcatheter arterial chemoembolization in the treatment of primary hepatocellular carcinoma. J Clin Hepatol 2010;13:286-7.

30. Liu Y. Hepatic arterial chemoembolization combined with gamma knife sequential therapy for advanced hepatocellular carcinoma. Public medical forum magazine 2014;18:1267-8.

31. Luo R. Clinical application of hepatic arterial chemoembolization combined with gamma knife sequential therapy in the treatment of advanced hepatocellular carcinoma. China Prac Med 2015;10:96-7.

32. Pan XF. Clinical observation of hepatic arterial chemoembolization combined with gamma knife in the treatment of primary hepatocellular carcinoma. Journal of Chinese Oncology 2015;21:311-5.

33. Sha XF. The therapeutic effect of primary hepatic carcinoma patients treated with hepatic arterial chemoembolization (TACE) combined with gamma knife ( $\gamma$-knife). Modern Oncology 2013;21:2281-3.

34. Song XY. Clinical application of transcatheter arterial chemoembolization combined with gamma knife sequential therapy in the treatment of intermediate-advanced hepatocellular carcinoma. China Continuing Medical Education 2016;25:80-1.

35. Sun X. Clinical application of hepatic arterial chemoembolization and gamma knife sequential therapy in the treatment of advanced hepatocellular carcinoma. Clinical Medicine 2014;8:80-1.

36. Wei SZ.Therapeutic effect of 52 primary hepatic carcinoma patients treated with hepatic arterial chemoembolization combined with gamma knife. Modern Oncology 2009;17:697-9.

37. Xiu L. Analysis on the curative effect of TACE combined with gamma knife in the treatment of primary hepatocellular carcinoma. Prac J Med 2011;28:309-10.

38. Yang XD. Evaluation of TACE combined with gamma-knife radiotherapy for primary hepatocellular carcinoma. J Intervent Radiol 2012;21:569-99.

39. Ye CP. Analysis of the efficacy of hepatic arterial chemoembolization combined with gamma knife in sequential treatment of advanced hepatocellular carcinoma. Journal of Fujian Medical University 2011;4:274-7.

40. Zhang X. Analysis of transcatheter arterial chemoembolization combined gamma knife in treatment of advanced hepatocellular carcinoma.China Modern Doctor. 2010;48:37-8.

41. Zhou P. Clinical study of transcatheter arterial chemoembolization combined with gamma knife for primary hepatic carcinoma. Med J West China 2011;23:1284-6. 